\title{
Dexmedetomidine is an Excellent Additive to Local Anaesthesia for Postoperative Analgesia in Bilateral Third Molar Teeth Extraction Surgery
}

\section{Ahmed Gamal Elsawy ${ }^{1, *}$ MD, Ahmed Maher Abouelnasr ${ }^{1}$ MD.}

* Corresponding Author:

Ahmed Elsawy

drahmedelsawy@azhar.edu.eg

Received for publication March 08, 2021; Accepted April 13, 2021; Published online April 13, 2021.

Copyright 2020 The Authors published by Al-Azhar University, Faculty of Medicine, Cairo, Egypt. All rights reserved. This an openaccess article distributed under the legal terms, where it is permissible to download and share the work provided it is properly cited. The work cannot be changed in any way or used commercially.

doi: $10.21608 /$ aimj.2021.66816.1430

${ }^{l}$ Department of Anesthesia and Intensiv Care, Faculty of Medicine, Al-Azho University, Egypt

\section{ABSTRACT}

Background: Extraction is still the primary treatment of choice for impact tooth under IANB or GA or a combination of both. Dexmedetomidine has been noticed to lengthen nerve blocks' range of duration, possibly due to the consequent vasoconstriction if combined with local anaesthetics.

Aim of the work: This study investigates the effect of injection of Dexmedetomidine as an additive to Lidocaine in IAN for patients undergoing lower bilateral impacted tooth extraction regarding analgesia's overall quality.

Patients and Methods: Sixty patients were randomized; 30 patients were in Group D and the other 30 in Group A. IANP was done bilaterally after GA using Lidocaine with Dexmedetomidine or Adrenaline. The primary outcome was the overall quality of analgesia and the whole demanded amount of analgesia. Hemodynamic parameters, patients and surgeon's satisfaction were recognized as secondary outcomes.

Result: The mean duration of local anaesthesia and postoperative analgesia time in Group (D) is $(259.0 \pm 11.5 \mathrm{~min})$ and $(362.3 \pm 12.3 \mathrm{~min})$, which is higher than Group (A) $(180.7 \pm 13.1)$ and $(231.4 \pm 13.1) .83 .3 \%$ of Group (D) received no analgesics, and $16.7 \%$ received one dose, while in Group (A), 50\% received two doses, 33.3\% received one dose, and $16.7 \%$ received no doses. VAS score was lower for Group (D) than (A) except for zero. The satisfaction was higher in Group (D) for both the patients and the surgeons.

Conclusion: Adding $12.5 \mu / \mathrm{ml}$ of Dexmedetomidine is an excellent additive to Lidocaine regarding the overall quality of analgesia, patient and surgeon satisfaction postoperatively.

Keywords: Third molar tooth; Impaction; Inferior alveolar nerve; Dexmedetomidine.

Disclosure: The authors have no financial interest to declare in relation to the content of this article. The Article Processing Charge was paid for by the authors.

Authorship: All authors have a substantial contribution to the article.

\section{INTRODUCTION}

Wisdom tooth erupts between the ages of 17 and $21^{\mathrm{i}}$. The eruption age varies between races, and it may be earlier in Nigerians as 14 yearsii and 27 years in European ${ }^{\text {iii. }}$. Due to malposition, space narrowing, or other barriers, the affected tooth is prevented from erupting into position ${ }^{\text {iv }}$. It accounts for up to 73 per cent of young adults in Europe ${ }^{v}$. It has the highest rate of being impacted ${ }^{\mathrm{vi}}$ in both sexes, but mostly in women $^{\text {vii }}$. Impaction complications such as decay, root resorption, pericoronitis, periodontitis, infections, cysts, tumors, mandibular fractures, and pain indicate immediate management. ${ }^{\text {viii ix }}$

Extraction is still the main treatment of choice for impact tooth under sole inferior alveolar nerve block (IANB) or general anaesthesia (GA) or a combination of both; depending on factors such as the patient's preference, the number of teeth to be extracted, depth of impaction and potential complications during the surgery ${ }^{6}$. However, most third molar extractions are carried out in the UK under $\mathrm{GA}^{9}$.

Local anaesthetics are often combined with Adjuvants to prolong the analgesia in single-injection nerve blocks such as Epinephrine, Opioids, Tramadol, Ketamine, Midazolam, Dexmedetomidine, Magnesium, Dexamethasone and Clonidine. ${ }^{\mathrm{x}}{ }^{\mathrm{xi}}$ ${ }^{x i i}$ Dexmedetomidine works primarily as an alpha-2 adrenoceptor agonist and has a seven-folds affinity to them than does clonidine. There are four subtypes of Alpha 2 adrenoceptors: $\alpha-2 \mathrm{~A}, \alpha-2 \mathrm{~B}, \alpha-2 \mathrm{C}$ and $\alpha-2 \mathrm{D}$. Vasoconstriction is caused mainly via $\alpha-2 \mathrm{~A}, \alpha-2 \mathrm{~B}$, and $\alpha-2 \mathrm{C}$ adrenoceptors as recognized pharmacologically ${ }^{\mathrm{xiii}} \quad{ }^{\mathrm{xiv}}$. Incorporating Dexmedetomidine into local anaesthetics has been found to prolong peripheral nerve blocks' duration, possibly due to the resulting local peripheral nerve vasoconstriction ${ }^{\mathrm{xvi}}$. 


\section{PATIENTS AND METHODS}

A prospective, randomized, double-blind research was performed at Sayed Galal Hospitals; Al-Azhar University, from January 2019 to August 2019, including 60 patients of the American Society of Anesthesiologists (ASA) I and II, aged 21-45 years, scheduled to undergo bilateral extraction of impacted third molar teeth under general anaesthesia, following approval by the Institutional Ethics Committee. Before commencing registration, all patients were told of the study's targets, processes, expected benefits and possible hazards. All patients have signed informed written consent. This study excluded patients with hypertension either controlled or not, ischemic heart disease, anticoagulant use, substance abuse, pregnancy or current lactation, and those with known allergies to any study medication. Also, surgery duration of more than 45 minutes was excluded. Randomization was conducted using a random number table created by the computer software of 60 patients assigned to two groups of 30 patients each.

1-Dexmedetomidine group (Group D): a dose of $4 \mathrm{ml}$ of $1 \%$ Lidocaine (Lidocaine 2\%, 20mg/mL, Hospira, USA) mixed with $12.5 \mu / \mathrm{ml}$ Dexmedetomidine (Precedex 200mcg/2ml, Pfizer, USA) was injected around the inferior alveolar nerve (IAN) in pterygomandibular fossa bilaterally.

2-Adrenaline group (Group A): $4 \mathrm{ml}$ of $1 \%$ Lidocaine with 1:100,000 Adrenaline (Adrenaline $1 \mathrm{mg} / 1 \mathrm{ml}$. Misr Co., Egypt) were injected around the IAN in pterygomandibular fossa bilaterally. The same surgeon has done the block and the surgery bilaterally.

The researchers have directed all patients about the Visual Analogue Scale (VAS) to assess pain severity during the anaesthesia clinic visit on 10 points scale $(0=$ No pain, $10=$ Worst tolerable pain $)$. All patients were monitored for vital signs at the preoperative preparation room and recorded as baseline data. After reassuring, all patients were premedicated with midazolam $0.03 \mathrm{mg} / \mathrm{kg}$ just before induction. After pre-oxygenating with $100 \%$ oxygen, induction was carried out in all patients using intravenous Lidocaine $1.5 \mathrm{mg} / \mathrm{kg}$, Propofol $2.5 \mathrm{mg} / \mathrm{kg} \mathrm{IV}$, Rocuronium $0.5 \mathrm{mg} / \mathrm{kg}$ IV and Remifentanil 1 $\mathrm{mcg} / \mathrm{kg}$ IV bolus, followed by $0.1 \mathrm{mcg} / \mathrm{kg} / \mathrm{min}$ IV infusion. The trachea was intubated with a nasal cuffed endotracheal tube after complete muscle relaxation followed by oropharyngeal packing with sterile wet gauze. Anaesthesia was maintained by Sevoflurane (2\% MAC in oxygen), intermittent topup doses of Rocuronium $(0.1 \mathrm{mg} / \mathrm{kg})$ if needed, guided by the train of four monitoring (TOF), and intermittent positive pressure ventilation was adjusted to maintain normocapnia $\left(\mathrm{EtCO}_{2}\right.$ around 35$45 \mathrm{mmHg}$ ). Continuous intraoperative monitoring of heart rate, noninvasive blood pressure, ECG, $\mathrm{EtCO}_{2}$, oxygen saturation and neuromuscular monitoring (TOF) was ensured. At the end of the operation, atropine $0.01 \mathrm{mg} / \mathrm{kg}$ and neostigmine $0.04 \mathrm{mg} / \mathrm{kg}$ were given to reverse the residual neuromuscular effect when a TOF ratio is 0.9 . in the recovery zone; the patients were monitored closely and assessed by the modified Aldrete score (MAS) ${ }^{\text {xvii }}$ until they were fully conscious, oriented to time, person and place
(MAS $\geq 9 / 12$ ). All patients received paracetamol 500 $\mathrm{mg}$ (QID) plus diclofenac potassium $50 \mathrm{mg}$ (BID). The postoperative pain intensity was estimated by visual analogue score (VAS) on 10 points scale $(0=$ No pain, $10=$ Worst tolerable pain). The first reading (VAS at 0 point) was recorded in the recovery room when the patient was fully recovered (MAS $\geq 9 / 12$ ), two, four, six, eight, 12, 16 and 24 hours postoperatively with the patient at rest in the ward or through a phone call by an anesthesiologist not involved in the preparation. Postoperative analgesia duration (the time elapsed between full recovery and the first analgesic request) was measured. Pethidine $25 \mathrm{mg}$ intravenous was given as rescue analgesia ondemand or when VAS was $\geq 4$ postoperatively. The rescue analgesia could be repeated to a maximum of $1 \mathrm{mg} / \mathrm{kg}$ body weight. The whole amount of analgesia demanded, and the frequency of doses was documented. The haemodynamic parameters (mean blood pressure and heart rate) were measured at baseline, 5, 10, 15, 20, 30, 40, 50 minutes, then at 1 , 2 and 4 hours postoperatively. The duration of local anaesthesia (indicated by the recovery of sensation to the lower lip) has been measured. Patient and surgeon satisfaction was verified on a 5-point Likert scale; (A type of quantitative response scale in which the participant clearly states their agreement level to a statement typically in five points: (1) Strongly disagree; (2) Disagree; (3) Neither agree nor disagree; (4) Agree; (5) Strongly agree) $)^{\mathrm{x} v i i i}$.

\section{Sample size calculation:}

The average duration for the duration of analgesia produced by adding Dexmedetomidine to local anaesthesia in the inferior alveolar block was 219 $\min ^{\text {xix }}$. Sample size calculated with the power of $80 \%$ and alpha of 0.05 to detect a difference of $30 \mathrm{~min}$, which is considered clinical significance, so the minimum of each group is 30 participants.

\section{Statistical analysis:}

Descriptive statistics for categorical variables were presented in frequencies and relative frequencies. The normally distributed numerical variables mean and standard deviation are used for the non-normally distributed numeric variables; the median and IQR were used. Comparing the categorical variables in the two groups was done using the Chi-Square test while comparing the numeric variables as time intervals, age, weight, pulse, blood pressure was done using independent $\mathrm{t}$-test. Comparison of the ordinal variables as VAS score and satisfaction level was made using Mann Whitney U test. IBM SPSS software for statistics, version 26 , was used for the analysis and p-value $<0.05$ was considered statistically significant.

\section{RESULTS}

Sixty patients were included and completed the study and were randomizes so that 30 patients were in the Dexmedetomidine group (Group D) and the other 30 in the Adrenaline group (Group A). There is no statistical significance in Sex, Age, ASA, Duration of surgery between the groups (Table1). 


\begin{tabular}{|c|c|c|c|}
\hline & $\begin{array}{l}\text { Group (D), } \\
\text { Mean (SD) }\end{array}$ & $\begin{array}{l}\text { Group (A), } \\
\text { Mean (SD) }\end{array}$ & $\begin{array}{c}\text { P- } \\
\text { value }\end{array}$ \\
\hline \multicolumn{4}{|l|}{ Sex } \\
\hline Male N (\%) & 16/30 (53.3) & 18/30 (60) & \multirow[t]{2}{*}{0.602} \\
\hline Female N (\%) & $14 / 30(47.7)$ & $12 / 30(40)$ & \\
\hline Age (year) & 26.1(8) & $27.0(8)$ & 0.641 \\
\hline Weight (kg) & $62.0(12)$ & $63.8(11.5)$ & 0.563 \\
\hline \multicolumn{3}{|l|}{ ASA } & \multirow{3}{*}{0.519} \\
\hline ASA I, N (\%) & $25(83.3)$ & $23(76.7)$ & \\
\hline ASA II, N (\%) & $5(16.7)$ & $7(23.3)$ & \\
\hline $\begin{array}{l}\text { Duration of } \\
\text { surgery (min) }\end{array}$ & $31.9(4.3)$ & $33.6(4.0)$ & 0.110 \\
\hline \multicolumn{4}{|c|}{$\begin{array}{l}\text { Data represented as Mean } \pm \text { SD and N (\%). ASA, } \\
\text { American Society of Anesthesiologist; Group(D), } \\
\text { Dexmedetomidine group; Group(A), Adrenaline } \\
\text { group. A P-value of less than } 0.05 \text { is statistically } \\
\text { significant. }\end{array}$} \\
\hline
\end{tabular}

Table1: Demographic characteristics of the two groups.

Comparison of the duration of local anaesthesia in the two groups showed a statistically significant difference. The mean duration in Group (D) is $259.0 \pm 11.5$ min which is higher than that of Group (A) $180.7 \pm 13.1 \mathrm{~min}$, p-value $<0.001$ (Table 2).

Comparison of the duration of postoperative analgesia in the two groups showed a statistically significant difference. The mean time in Group (D) is $362.3 \pm 12.3 \mathrm{~min}$, which is higher than Group (A) 231.4 $\pm 13.1 \mathrm{~min}$ (Table 2).

Comparing the analgesic requirements during the first 24 hours in the two groups showed a statistically significant difference. 83.3\% of Group (D) received no analgesics, and $16.7 \%$ received one dose, while in Group (A), 50\% received two doses, 33.3\% received one dose, and $16.7 \%$ received no doses. Also, there is an increase in total analgesic requirements $(\mathrm{mg})$ in Group (D) compared to Group (A) $33.3 \pm 18.95$ and 4.16 \pm 9.47 , respectively (Table 2 )

\begin{tabular}{|c|c|c|c|}
\hline & $\begin{array}{l}\text { Group } \\
\text { (D), } \\
\text { Mean } \\
\text { (SD) }\end{array}$ & $\begin{array}{l}\text { Group } \\
\text { (A), } \\
\text { Mean } \\
\text { (SD) }\end{array}$ & P-value \\
\hline $\begin{array}{l}\text { Duration of local } \\
\text { anaesthesia } \\
\text { (min.) }\end{array}$ & $\begin{array}{l}259.0 \\
(11.5)\end{array}$ & $\begin{array}{l}180.7 \\
(13.1)\end{array}$ & $<0.001 * *$ \\
\hline $\begin{array}{l}\text { Duration of } \\
\text { postoperative } \\
\text { analgesia (min.) }\end{array}$ & $\begin{array}{l}362.3 \\
(12.3)\end{array}$ & $\begin{array}{l}231.4 \\
(13.1)\end{array}$ & $<0.001 * *$ \\
\hline $\begin{array}{l}\text { Total analgesic } \\
\text { requirements } \\
\text { (mg) }\end{array}$ & $4.16 \pm 9.47$ & $\begin{array}{c}33.3 \pm 18 \\
95\end{array}$ & $<0.001 * *$ \\
\hline \multicolumn{3}{|c|}{ Frequency of analgesia request } & \multirow{4}{*}{$<0.001^{* *}$} \\
\hline \multirow{3}{*}{$\begin{array}{l}\text { None, } \mathbf{N}(\%) \\
\text { One dose, } \mathbf{N}(\%) \\
\text { Two doses, } \mathbf{N} \\
(\%)\end{array}$} & $25(83.3)$ & $5(16.7)$ & \\
\hline & $5(16.7)$ & $10(33.3)$ & \\
\hline & $0(0)$ & $15(50)$ & \\
\hline
\end{tabular}

Data represented as mean \pm SD and $n(\%)$. Group(D), Dexmedetomidine group; $\operatorname{Group}(\mathrm{A})$, Adrenaline group. A P-value of less than 0.05 is statistically significant. $* *$ highly significant data.

Table 2: Comparison of the two groups regarding the duration of local anaesthesia, analgesia duration, total analgesic requirements, frequency of analgesia request:

In all VAS assessments during the first 24h, the VAS score was lower for Group (D) than Group (A) except for zero, where there was no difference between the two groups (Table 3 ).

\begin{tabular}{|c|c|c|c|}
\hline & $\begin{array}{c}\text { Group (D) } \\
\text { median } \\
\text { (IQR) }\end{array}$ & $\begin{array}{c}\text { Group } \\
\text { (A) } \\
\text { median } \\
\text { (IQR) }\end{array}$ & P-value \\
\hline VAS 0 & $1(1,1)$ & $1(1,1.3)$ & 0.537 \\
\hline VAS 2 & $1(1,2)$ & $2(1,3)$ & 0.049 \\
\hline VAS 4 & $2(1,2)$ & $3(3,4)$ & $<0.001^{* *}$ \\
\hline VAS 6 & $2(2,2)$ & $3(3,4)$ & $<0.001^{* *}$ \\
\hline VAS 8 & $2(2,2)$ & $3(3,5)$ & $<0.001^{* *}$ \\
\hline VAS 12 & $2(2,3)$ & $3(3,3)$ & $<0.001^{* *}$ \\
\hline VAS 16 & $2(2,3)$ & $3(3,4)$ & $<0.001^{* *}$ \\
\hline VAS 24 & $2(2,3)$ & $3(3,3)$ & $<0.001^{* *}$ \\
\hline
\end{tabular}

Data represented as median (interquartile range). Group(D), Dexmedetomidine group; Group(A), Adrenaline group. A P-value of less than 0.05 is statistically significant. $* *$ highly significant data.

Table 3: Comparison of the two groups regarding anaesthesia VAS score.

The satisfaction level for both the patients and the surgeons was higher in Group (D) than the Group (A). (Table 4, Figure1\&2) illustrates this difference.

\begin{tabular}{|c|c|c|c|}
\hline & $\begin{array}{l}\text { Median } \\
\text { (IQR) }\end{array}$ & $\begin{array}{c}\text { Median } \\
\text { (IQR) }\end{array}$ & P-value \\
\hline $\begin{array}{r}\text { Patient's } \\
\text { Satisfaction }\end{array}$ & $4.5(4,5)$ & $3(3,4)$ & $<0.001^{* *}$ \\
\hline $\begin{array}{l}\text { Surgeon's } \\
\text { satisfaction }\end{array}$ & $5(4,5)$ & $3(3,4)$ & $<0.001^{* * *}$ \\
\hline
\end{tabular}

Table 4: Comparison of the two groups regarding satisfaction.

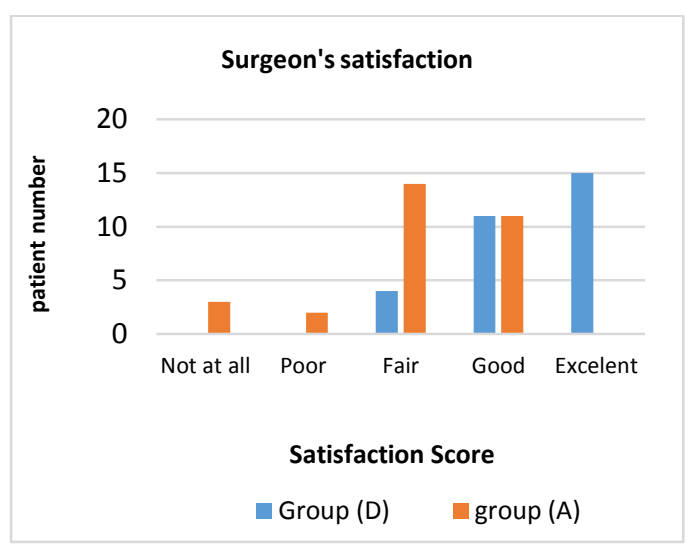

Fig. 1: Comparison of Surgeon's satisfaction in the two groups. 


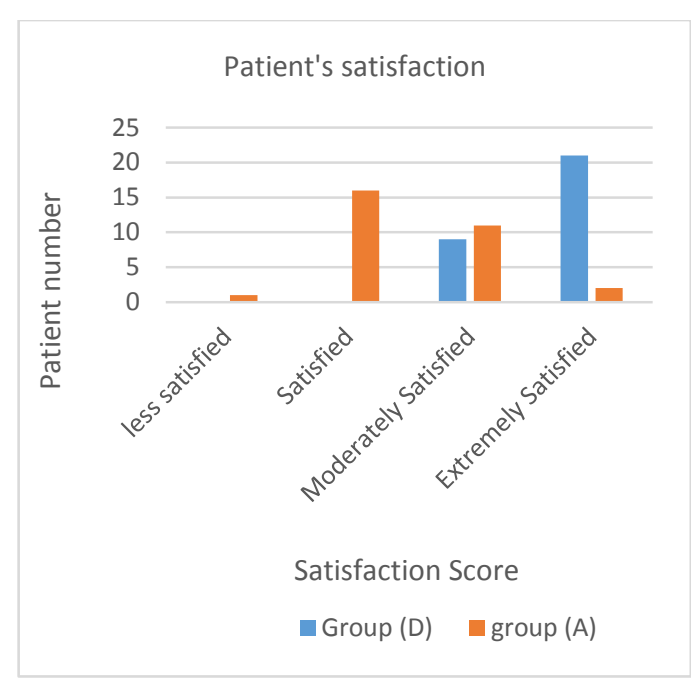

Fig. 2: Comparison of Patient's satisfaction in the two groups.

For all the heart rates assessed, the pulse was lower for Group (D) than Group (A) except for zero, where there was no difference between the two groups (Figure 3).

For all the mean blood pressure measurements, the mean BP was lower for Group (D) than Group (A) except for zero and four hrs, where there was no difference between the two groups (Figure 4).

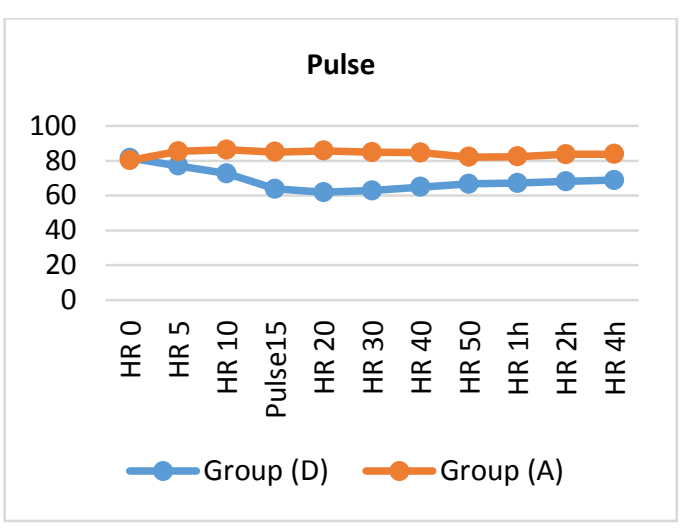

Fig. 3: Comparison of pulse rate in the two groups.

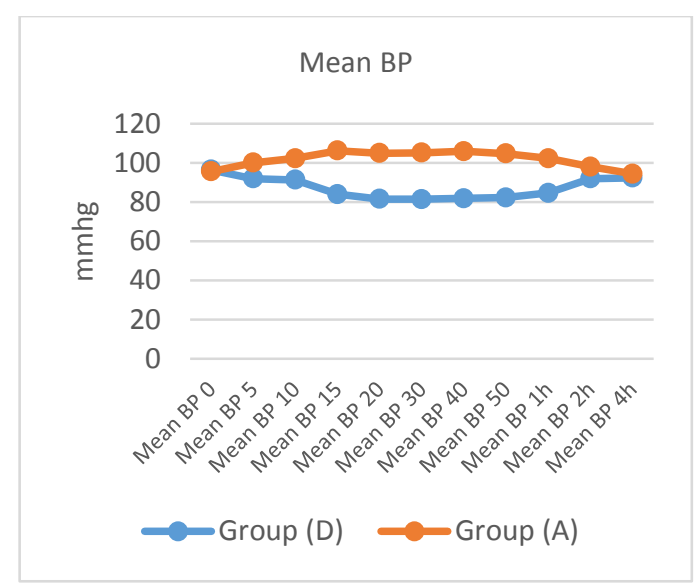

Fig. 4: Comparison of the mean BP in the two groups

\section{DISCUSSION}

Most local anaesthesia used in dentistry anaesthesia should be complemented by vasoconstrictive agents. to increase the duration and maximize efficacy. As the severity of pain after third molar surgery reaches the maximum at 3 to 5 hours after surgery, ${ }^{x x}$. However, dentists ought to be very conscious of the use of vaso-constrictors mediated by alpha- 1 receptors in medically compromised patients ${ }^{\mathrm{xxi}}$. Also, adjuvants help to reduce the dose of local anaesthetic. Opioids such as Fentanyl, Sufentanil, Morphine, and non-opioids include Epinephrine, alpha-2 agonist Clonidine, and nonsteroidal antiinflammatory drugs, $\mathrm{Mg}^{2+}$, and $\mathrm{NaHCO}_{3}$ and $\mathrm{NaHCO}_{3}$, have commonly used adjuvants. Alpha 2Adrenoceptor agonists, such as DEX, produce sympatholytic, sedative, analgesic, antihypertensive, and bradycardic effects. Dexmedetomidine has been discovered to extend the peripheral nerve blocks' duration range if joint with a local anaesthetic agent due to local vasoconstriction ${ }^{\text {xxii }}$. The vasoconstricting effect of Dexmedetomidine on the peripheral alpha-2 vessel receptors can intensify the influence of Lidocaine. ${ }^{\text {xxii xxiv }}$

There was a significant difference in our analysis between the two groups regarding the duration of action of local anaesthesia and postoperative analgesia duration in the two groups. These findings are backed by Kumar 2016, which has shown that Dexmedetomidine is valuable for extending local anaesthesia. They showed that Dexmedetomidine was added to lignocaine and increased the mandibular and maxillary nerve block time (156 \pm 86.4$)$ for $(85.8 \pm 81.7)$ P-value $<0.05$, analgesia duration not only this but also faster onset of action in patients undergoing orthodontic extraction ${ }^{\mathrm{xxv}}$. Another crossover double-blinded study done by Yamane et al. showed injecting Dexmedetomidine with lidocaine increase the effectiveness and duration xxvi . On the same line came the results of Tonooka $\&$ Sunada 2018, who reported that the dose of 12.5 $\mu \mathrm{g} / \mathrm{mL}$ DEX added to Lidocaine enhances its influence and expands its duration compared to Lidocaine alone $e^{\text {xxvii }}$

Vasoconstrictors are added to local anaesthetics in surgeries of the oral cavity to prolong the time of action. High blood flow increases the systemic absorption, increasing the incidence of systemic toxicity and decreasing the time of action ${ }^{27}$. Adjuvants have been added to local anaesthesia like opioids (Fentanyl, Sufentanil, and Morphine) or nonopioids such as anti-inflammatory drugs, Epinephrine, Clonidine, $\mathrm{Mg}^{2+}$, and $\mathrm{NaHCO}_{3}$ were established mainly to increase the duration, potency and decrease the dose $\mathrm{e}^{21}$.

By vasoconstriction, Dexmedetomidine improves the local anaesthetic action of Lidocaine through $\alpha-2 \mathrm{~A}$, $\alpha-2 B$ and $\alpha-2 C$ adrenoceptors around the injection area as reported via an animal model using a sedated tail-flick, ${ }^{\text {xxviii }}$.in addition, vasoconstriction inhibits the nociceptive impulse transmission along myelinated $\mathrm{C}$ fibres ${ }^{\mathrm{xxix}}$.

Dex is an alpha-2adrenoceptors agonist which has analgesic, sedative, anxiolytic action. 
Dexmedetomidine inhibits neurotransmission by decreasing the compound action potential in a dosedependent fashion peripherally ${ }^{\mathrm{xxx} \text { xxxi. }}$. More ever, it has been recognized to inhibits substance $\mathrm{P}$ release centrally via activation of alpha-2adrenoceptors in the locus coeruleus and the nociceptive pathway at the dorsal root neuron-level. ${ }^{\mathrm{xxii}}$

We found that the mean BP in Group (D) fell compared to Group (A), except zero and four. In agreement with Yoko Tonooka and Katsuhisa Sunada 2018, an evident decline in blood pressure was demonstrated between 20 and 50 minutes was verified. ${ }^{27}$.

Also, Ouchi and Sugiyama 2016 attempted different doses of dex. They showed that $13.5 \mu \mathrm{g} / \mathrm{ml}$ of DEX was associated with a drop of mean bp at 30 to 60 minutes to some level from the baseline but not hypotension as we figured ${ }^{18}$.

Nevertheless, on the other side, Kumar et al. 2016 reported no blood pressure change ${ }^{21}$ as per Yamane et al., 2015, who demonstrated that $0.7 \mathrm{ug} / \mathrm{ml}$ DEX displaying no blood pressure influence ${ }^{26}$.

Regarding the heart rate, we observed the pulse was lower for group D than group A except for zero, as reported by Kumar et al. 2016 as they found a minor decrease in the heart rate in the DEX group ${ }^{25}$. However, Yamane et al. 2015 did not see a change in the heart rate using $0.7 \mu \mathrm{g} / \mathrm{ml}^{26}$. Also, a range of doses ranging from 4.5-13.5 $\mu \mathrm{g} / \mathrm{ml}$ Ouchi and Sugiyama 2016 could not report a difference in heart rate $^{18}$.

Yoko Tonooka and Katsuhisa Sunada 2018 agreed that local injection of dex with Lidocaine in the oral

i Khan NB, Chohan AN, AlMograbi B, et al. Eruption Time of Permanent First Molars and Incisors Among a Sample of Saudi Male Schoolchildren. Saudi Dent J. 2006 JanApr;18(1):18-24.

ii Odusanya SA and Abayomi IO. Third molar eruption among rural Nigerians. Oral Surg Oral Med Oral Pathol. 1991 Feb;71(2):151-4.

iii Kruger E, Thomson WM and Konthasinghe P. Third molar outcomes from age 18 to 26: findings from a population-based New Zealand longitudinal study. Oral Surg Oral Med Oral Pathol Oral Radiol Endod. 2001 Aug;92(2):150-5.

iv Archer WH. Oral Surgery: A Step-By-Step Atlas of Operative Techniques, 4th ed. Philadelphia: W.B. Saunders Company; 1966. p. 507-10.

v Pahkala R, Pahkala A and Laine T. Eruption pattern of permanent teeth in a rural community in northeastern Finland. Acta Odontol Scand. 1991 Dec;49(6):341-9. cavity has a systemic effect on the BP and HR, although this effect may be evident after some time due to vasoconstriction. Heart rate was the first to be affected, as they reported ${ }^{27}$.

The Surgeon satisfaction was higher in Group (D) than the Group (A), which can be explained by the minimal drop of blood pressure and heart rate, which assist the vasoconstriction in improving the surgical field and reducing the bleeding without affection cardiovascular stability. The prolonged tense effect might explain the higher patient satisfaction rate due to combined peripheral and central action and the light sedation state produced by DEX. This is supported by the results of Ross et al. 1998, who evaluated 106 patient's preoperative attitude to third molar extraction under general anaesthetics as a day case. He found that $96 \%$ of patients were happy to be treated as such. Postoperatively, 91\% were satisfied $^{\text {xxxiii }}$

\section{CONCLUSION}

We concluded that adding $12.5 \mu / \mathrm{ml}$ of Dexmedetomidine is an excellent additive to Lidocaine in Inferior alveolar nerve block as regard to the duration of local anaesthesia, postoperative analgesia, potency of the block, patient and surgeon satisfaction in bilateral third molar teeth surgery.

\section{REFERENCES}

vi Santosh P. Impacted mandibular third molars: review of literature and a proposal of a combined clinical and radiological classification. Ann Med Health Sci Res. 2015; 5(4): 229-34.

vii Blondeau F and Daniel NG. Extraction of impacted mandibular third molars: postoperative complications and their risk factors. Journal of the Canadian Dental Association. 2007; 73(4): 325 e. $6 \mathrm{p}$.

viii Torres MAF, Albiol JG, Aytes BL, et al. Evaluation of indications for surgical removal of 3rd molars according to oral surgeon and primary care dentist. Experience in the Master of Oral surgery and Implantology at Barcelona University Dental school. Med Oral Patol Oral Cir Bucal. 2008; 13(8): 499-504.

ix Rafetto LK. Managing impacted third molars. Oral and maxillofacial surgery clinics of North America. 2015; 27(3): 363-371.

\section{.} Anesthesia 
x Bailard NS, Ortiz J and Flores RA. Additives to local anesthetics for peripheral nerve blocks: evidence, limitations, and recommendations. $A m$ J Health Syst Pharm 2014;71:373-85.

xi Swain A, Nag DS, Sahu S, et al. Adjuvants to local anesthetics: current understanding and future trends. World J Clin Cases 2017;5:30723

xii Knight JB, Schott NJ, Kentor ML, et al. Neurotoxicity of common peripheral nerve block adjuvants. Curr Opin Anaesthesiol 2015;28:598-604.

xiii Duka I, Gavras I, Johns C, et al. Role of the postsynaptic alpha(2)-adrenergic receptor subtypes in catecholamine-induced vasoconstriction. General pharmaco. 2000;134:101-6.

xiv Snapir A, Koskenvuo J, Toikka J, et al. Effects of common polymorphisms in the alpha1A-, alpha2B-, beta1- and beta2adrenoreceptors on haemodynamic responses to adrenaline. ClinSci. 2003;104:509-20.

xv Chotani MA, Mitra S, Su BY, et al. Regulation of alpha(2)-adrenoceptors in human vascular smooth muscle cells. Am $J$ physiol Heart circ physio. 2004; 1286:H59-67.

xvi Ramadhyani U, Park JL, Carollo DS, et al. Dexmedetomidine: Clinical application as an adjunct for intravenous regional anesthesia. Anesthesiol Clin 2010;28:709-22.

xvii Aldrete JA. The post-anesthesia recovery score revisited. J Clin Anesth. 1995; 7(1):89-91.

xviii 5-Point Likert Scale. In: Preedy V.R., Watson R.R. (eds) Handbook of Disease Burdens and Quality of Life Measures. Springer, New York, NY. https://doi.org/10.1007/978-0-387-786650_6363

xix Kentaro Ouchi and Kazuna Sugiyama. Dexmedetomidine Dose Dependently Enhances the Local Anesthetic Action of Lidocaine in Inferior Alveolar Nerve Block: A Randomized Double-Blind Study. Regional anesthesia pain Med. May-Jun 2016;41(3):348-55.

xx Coulthard P. Post-operative oral surgery pain: a review. Oral Surgery. 2008;1(4):167-77. xxi Cannell H. Evidence for safety margins of lignocaine local anaesthetics for peri-oral use. Br Dent J. 1996;181(7):243-9.

xxii Kentaro Ouchi, Yoshihisa Koga, Shinichi Nakao et al. Dexmedetomidine dosedependently enhances local anesthetic action of lidocaine. J Oral Maxillofac Surg. 2014 Mar;72(3):474-80.

xxiii Iida $\mathrm{H}$, Ohata $\mathrm{H}$, Iida $\mathrm{M}$, et al. Direct effects of al - and a2 -adrenergic agonists on spinal and cerebral pial vessels in dogs. Anesthesiology. 1999; 91:479-485.

xxiv Masuki S, Dinenno FA, Joyner MJ, et al. Selective alpha2-adrenergic properties of dexmedetomidine over clonidine in the human forearm. J Appl Physiol. 2005;99: 587-592.

xxv Prashant Kumar, Manju Thepra, Amrish Bhagol, et al. The newer aspect of dexmedetomidine use in dentistry: As an additive to local anesthesia, initial experience, and review of literature. J Maxillofac Surg. 2016 Jan-Jun; 7(1): 76-79.

xxvi Ayaka Yamane, Hitoshi Higuchi, Yumiko Tomoyasu, et al. Effect of dexmedetomidine injected into the oral mucosa in combination with lidocaine on local anesthetic potency in humans: a crossover double-blind study. J Oral Maxillofac Surg. 2015 Apr;73(4):616-21.

xxvii Yoko Tonooka and Katsuhisa Sunada. Dexmedetomidine Enhances the Pulpal Anesthetic Effect of Lidocaine: A Pilot Study. the American Dental Society of Anesthesiology Anesth Prog. 2018; 65:38-43.

xxviii Ouchi K, SekineJ, Koga Y, et al. Establishment of an animal model of sedation using epidural anesthesia that uses the tail-flick test for evaluating local anesthetic effects in rats. ExpAnim 2013; 62:137-44.

xxix Johansson A, Hao J and Sjölund B. Local corticosteroid application blocks transmission in normal nociceptive C-fibres. Acta Anaesthesiol Scand 1990;34:335-8.

xxx Memis D and Turan A, Karamanlioglu B, Pamukçu Z, Kurt I. Adding dexmedetomidine to lidocainefor intravenous regional anesthesia. Anesth Analg. 2004;98:835-40. 
xxxi Abdallah FW and Brull R. Facilitatory effects of perineural dexmedetomidine on neuraxial andperipheral nerve block: A systematic review and meta-analysis. $\mathrm{Br} J$ Anaesth. 2013;110:915-25.

xxxii Kroin JS, Buvanendran A, Williams DK, et al. Local anesthetic sciatic nerve block and nerve fiber damage in diabetic rats. Reg Anesth Pain Med. 2010; 35:343-50.

xxxiii Ross M. An assessment of patients attitudes to day-case general anesthesia for removal of mandibular third molars. British Journal of Oral and Maxillofacial Surgery. 1998;36(1):27-9. 